\title{
RELEVÂNCIA DA CERTIFICAÇÃO ISO 9001:2008 NA INFLUÊNCIA DE COMPRA DE PRODUTOS
}

\author{
RAFAEL MATTA CARNASCIALI \\ SAMUEL F. DE MELO
}

\begin{abstract}
RESUMO
Este artigo teve como objetivo verificar a relevância da certificação ISO 9001:2008 na influência de compra de produtos. Para isso, realizou-se uma pesquisa exploratória por meio de livros e artigos científicos e uma aplicação prática em alunos da Universidade Federal do Paraná. O estudo contou com o teste piloto $A$, o teste piloto $B$ e a aplicação do estudo, em que foram criadas embalagens de lâmpadas, com selo e sem o selo de empresa certificada ISO 9001. Desta forma, buscou-se verificar se no ato de compra de um produto há relevância da certificação ISO 9001:2008 para a escolha do produto. O resultado da pesquisa demonstrou que há relevância da certificação ISO 9001 na influência de compra de produtos, mas também verificou que poucos participantes sabem do que se trata a certificação ISO 9001:2008.
\end{abstract}

Palavras Chaves: Gestão da qualidade, ISO 9001:2008, selo de certificação.

\begin{abstract}
This article aimed to verify the relevance of ISO 9001:2008 certification in influencing purchase products. For this, there was an exploratory research through books and scientific papers and a practical application in students of the Federal University of Paraná. The study included the pilot A, pilot B testing and the application of the study, in which lamps packages were created, with stamp and without the company seal certified ISO 9001. Therefore, we sought to determine whether the act of purchase of a product 's relevance of ISO 9001:2008 certification for product choice. The research result showed that there is relevance of ISO 9001 in the influence of purchasing products, but also found that few participants know what it is ISO 9001:2008.
\end{abstract}

Keywords: Quality management, ISO 9001:2008, certification seal. 


\section{INTRODUÇÃO}

A implantação de um sistema de gestão da qualidade representa a obtenção de uma ferramenta que possibilita a otimização de diversos processos dentro da organização, além de evidenciar a preocupação com a melhoria contínua dos produtos e serviços fornecidos (ABNT NBR ISO 9001:2008). No entanto, segundo os autores Abicht et al (2008), a certificação ISO 9001 possibilita a implementação, manutenção e melhoria de um sistema de gestão da qualidade para a empresa, mesmo que as características do produto ou serviço não atendam às necessidades dos clientes.

De acordo com Marín Vinuesa (2013) os principais estudos que dizem respeito as vantagens e benefícios decorrentes da certificação ISO 9001 apresentam resultados diversos e contraditórios. Ainda segundo a autora, isso pode ser, porque os motivos que orientam a decisão de certificação podem influenciar os resultados que dela decorrem. Os benefícios derivados da certificação ISO 9001:2008 não são os mesmos para todas as empresas, pois dependem dos objetivos de qualidade e do compromisso empregado para alcançar a excelência empresarial (POKSINSKA, 2010).

Para D'Ângelo e Neto (2008), os fatores mais comuns que motivam as empresas brasileiras na busca da certificação são as exigências de clientes, pois o não atendimento dessas significa a perda das vendas e, outro fator, relaciona-se à possibilidade de usar a certificação como autopromoção, buscando assim, uma diferenciação no mercado.

Uma das formas que as empresas utilizam para realizar a autopromoção é por meio das embalagens que envolvem seus produtos. Desta forma, são criados selos que as identificam como empresas certificadas, e estes selos são impressos nas embalagens, já que as certificadoras e a ISO, as proíbem de utilizar seus logotipos em embalagens.

Tendo em vista que a marca se apresenta cada vez mais como um fator determinante para a e diferenciação e o posicionamento de empresas e produtos, podese dizer que a marca representa a "experiência total entre o consumidor e uma empresa". Segundo Pelegrini e Kistmann (2010), a experiência se manifesta através dos produtos, da comunicação, do ambiente, da embalagem, da identidade corporativa. Ou seja, por meio de todas as interfaces, tanto as tangíveis, quanto as intangíveis, que uma empresa estabelece contato com o seu público. Dentro deste contexto a embalagem assume um papel fundamental para o estabelecimento dos laços necessários para a manutenção da fidelidade a uma marca (PELEGRINI; KISTMANN, 2003). É com esse propósito que algumas empresas buscam a certificação, podendo assim, criar um selo para estampa-lo como forma de divulgar o feito. 
Especialistas da área ressaltam que as empresas certificadas sob a pressão de agentes externos ou por questões de imagem e autopromoção, sentem maior dificuldade em melhorar o seu desempenho através deste sistema de qualidade (BROWN, VAN DER WIELE, LOUGHTON, 1998; LEUNG, CHAN, LEE, 1999).

Diante das motivações empresariais apontadas para a busca de certificação ISO 9001:2008, verifica-se uma relação paradoxal, pois de um lado a implantação tem como objetivo uma melhoria de dentro para fora, sob o aspecto de um sistema de gestão e de outro lado a implantação com o intuito de uma melhoria de fora para dentro por meio da autopromoção ou pressão de agentes externos.

Pretende-se com este estudo verificar, sob o olhar do consumidor, qual a relevância da certificação ISO 9001:2008 na influência de compra de produtos. Para a realização deste trabalho, foram criadas embalagens de lâmpadas, com selo e sem o selo de empresa certificada ISO 9001. Desta forma, buscou-se em uma pesquisa exploratória, verificar se no ato de compra de um produto há a relevância da certificação ISO 9001:2008 para a escolha do produto. Pretende-se também com este estudo, verificar se a estratégia de certificação ISO 9001:2008 utilizada por empresas para autopromoção e utilização de imagem resultam realmente em vantagens mercadológicas e benefícios empresariais.

Além desta seção introdutória, compõe este artigo outras 5 (cinco) seções. A seção 2 (dois), que aborda o Sistema de Gestão da Qualidade ISO 9001, a seção 3 (três) em que é abordada a metodologia adotada para esta pesquisa, a seção 4 (quatro) corresponde a análise dos dados, a seção 5 (cinco), refere-se a discussão e, por fim, a 6 (seis) apresenta a conclusão e as considerações finais.

\section{SISTEMA DE GESTÃO DA QUALIDADE - NORMA ISO 9001:2008}

Com a revisão da Norma ISO 9001:2008, em que se orienta a adoção da abordagem de processos, a melhoria contínua e a satisfação dos clientes, a qualidade total passou a fazer parte da política empresarial e tornou-se uma das premissas para a sobrevivência das organizações (OLIVEIRA, 2009). Nesse sentido, algumas organizações, para garantirem padrões de qualidade, seguem preceitos de organismos mundiais, do tipo International Organization for Standardization (ISO), do qual o Brasil é país membro e representado pela Associação Brasileira de Normas Técnicas (ABNT). Portanto, tratase de uma organização internacional com sede em Genebra, na Suíça, fundada em 1946, 
que tem como objetivo o desenvolvimento de normas técnicas para o estabelecimento de padrões internacionais de gestão que são aplicadas em organizações de todo o mundo (CORREIA; MELO; MEDEIROS, 2006).

As Normas da Série ISO 9000 foram desenvolvidas como forma de padronizar a implantação de Sistemas de Gestão de Qualidade (SGQ) (TROTT, 2012) e apresentam forte apelo comercial em alguns nichos de mercado, incentivando vendas e estabelecendo parcerias comerciais (VALLS, 2005; FRANCESCHINI; GALLETO; CECCONI, 2006). A série de normas ISO 9000 é composta pelas normas: ISO 9000, que apresenta fundamentos e vocabulário; ISO 9001, que é a norma certificável, apresentando os requisitos básicos para um SGQ; e a ISO 9004, que apresenta recomendações para a melhoria do desempenho dos SGQs (CORREIA; MELO; MEDEIROS, 2006).

A norma ISO constitui um denominador comum de boas práticas industriais voltadas para a qualidade e serve de guia para a implantação de sistemas de qualidade (WOOD JR.; URDAN, 1994).

A última versão da norma ISO 9001 foi publicada em novembro de 2008, sendo esta sua quarta edição. Em comparação com as versões anteriores, a estrutura e os conceitos da norma evoluíram consideravelmente, assumindo uma nova abordagem. 0 vocabulário foi simplificado e apresentou maior facilidade de utilização por parte das empresas de serviços além da conformidade com as normas de gestão ambiental ISO 14000 (PINTO; CARVALHO; HO, 2006).

Espera-se, com a implementação e certificação do padrão de qualidade ISO 9000, a melhoria do desempenho da empresa, permitindo a redução de custos de qualidade e, consequentemente, os custos de produção. Com o cumprimento da Norma ISO, entende-se que os processos estejam adequadamente controlados para garantir a entrega de produtos livres de defeitos. Entretanto, para Trott (2012), a conformidade com a Norma ISO 9001 nada diz sobre a qualidade real do produto.

Para D'Ângelo e Neto (1997) a implementação de um sistema da qualidade não implica necessariamente em obter certificação, pois os benefícios decorrentes da implementação do sistema da qualidade independem da certificação. 


\section{METODOLOGIA}

A classificação da metodologia de pesquisa pode ser dividida quanto aos objetivos gerais, à natureza da pesquisa e a sua abordagem (GIL, 2002; SILVA, MENEZES, 2001). Quanto aos objetivos, esta pesquisa se caracteriza como sendo exploratória, pois visa proporcionar maior familiaridade com o problema, com vistas a torná-lo mais explícito e a construir hipóteses. Quanto a natureza, esta pesquisa pode ser considerada aplicada, pois objetiva gerar conhecimentos para aplicação prática, dirigidos à solução de problemas específicos. Quanto ao tipo de abordagem, esta pesquisa se caracteriza como sendo quantitativa, pois seus resultados podem ser quantificados (GIL, 2007).

Esta pesquisa foi aplicada na Universidade Federal do Paraná (UFPR), contando com a participação dos alunos de diversos cursos, abordados de forma aleatória no Setor de Educação Profissional e Tecnológica e Prédio da Administração do Centro Politécnico. Desta forma, participaram alunos dos cursos de Arquitetura, Ciência da Computação, Matemática, Tecnologia em Gestão da Qualidade (TGQ), Tecnologia em Secretariado Executivo (TSE), Tecnologia em Produção Cênica (TPC), Tecnologia em Negócios Imobiliários (TNI), Tecnologia em Análise e Desenvolvimento de Sistemas (TADS), Tecnologia em Comunicação Institucional (TCI), Tecnologia em Gestão Pública (TGP).

Com o objetivo de verificar a relevância da certificação ISO 9001 na influência de compra de produtos, foram realizadas três etapas para a aplicação da pesquisa, o teste piloto $A$ e a adequação do estudo, o teste piloto $B$ e adequação do estudo e a aplicação do estudo.

O teste piloto A foi aplicado no segundo semestre de 2014. O teste piloto B foi realizado no dia 6 de maio de 2015. A aplicação do estudo foi realizada nos dias 19, 25 e 28 de maio e 4 e 11 de junho de 2015.

\section{1 Teste piloto A e adequação do estudo}

Para o teste piloto $\mathrm{A}$, foram criadas duas embalagens de lâmpadas com diferentes designs, embalagem E1 e embalagem E2, que foram apresentadas a 21 (vinte e um) alunos participantes da pesquisa. Estes tiveram que escolher qual das lâmpadas comprariam, sendo que a embalagem E1 apresentava o selo de empresa certificada ISO 9001 e a embalagem E2 não apresentava selo de empresa com certificação ISO 9001. Portanto, de forma hipotética, as lâmpadas apresentavam embalagens distintas, custavam o mesmo preço e tinham as mesmas especificações técnicas, sendo que uma 
apresentava selo de empresa certificada pelo ISO 9001 e outra não. O selo e as embalagens utilizados foram criados especialmente para a realização desta pesquisa (FIGURA 1).

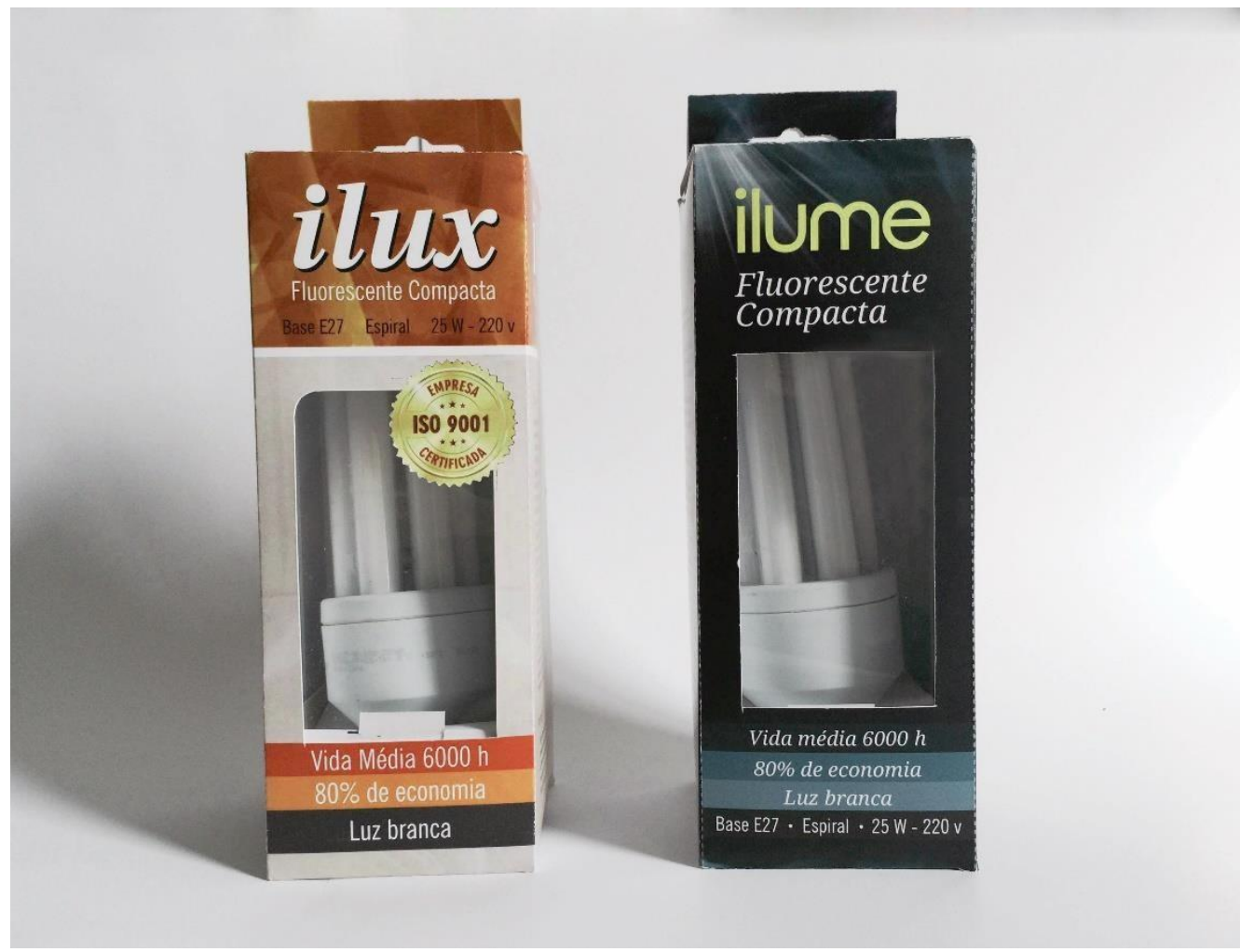

FIGURA 1 - TESTE PILOTO A (EMBALAGENS E1 E E2)

FONTE: autores (2014).

O teste piloto A revelou pouca influência da certificação ISO 9001:2008 no processo de escolha e compra do produto pelo cliente. Das 21 (vinte e uma) pessoas que participaram do teste, apenas 1 (uma) pessoa escolheu a embalagem E1, com o selo de certificação ISO 9001, e a escolha não se deu por conta do selo de certificação da empresa e sim por causa do design da embalagem. 20 (vinte) pessoas escolheram a embalagem E2, sem o selo, por causa do design. Segundo o relato de um participante que escolheu a embalagem E2, o selo de certificação não apresentava nenhuma serventia para ele no momento da compra de um produto.

Após a realização do teste piloto $\mathrm{A}$, foi realizado uma adequação da proposta. Nesta nova proposta de teste, foi desenvolvida a criação de uma nova embalagem. Esta nova embalagem, adotou-se como sendo embalagem E3. A embalagem E3 apresentou-se com o mesmo design da embalagem E2, com a diferença de que a embalagem E3 possuía $\begin{array}{llllll}\text { o selo } & \text { de } & \text { empresa } & \text { certificada } & \text { ISO }\end{array}$ 


\section{1 Teste piloto B e adequação do estudo}

Para o teste piloto B foi criada a embalagem E3 e, juntamente com a embalagem E2, as duas embalagens com lâmpadas foram apresentadas a 7 (sete) alunos participantes da pesquisa. Estes tiveram que escolher qual das lâmpadas comprariam, sendo que ambas as embalagens apresentavam o mesmo design, custavam o mesmo preço e tinham as mesmas especificações técnicas, com a diferença da presença do selo de empresa certificada em uma das embalagens (FIGURA 2).

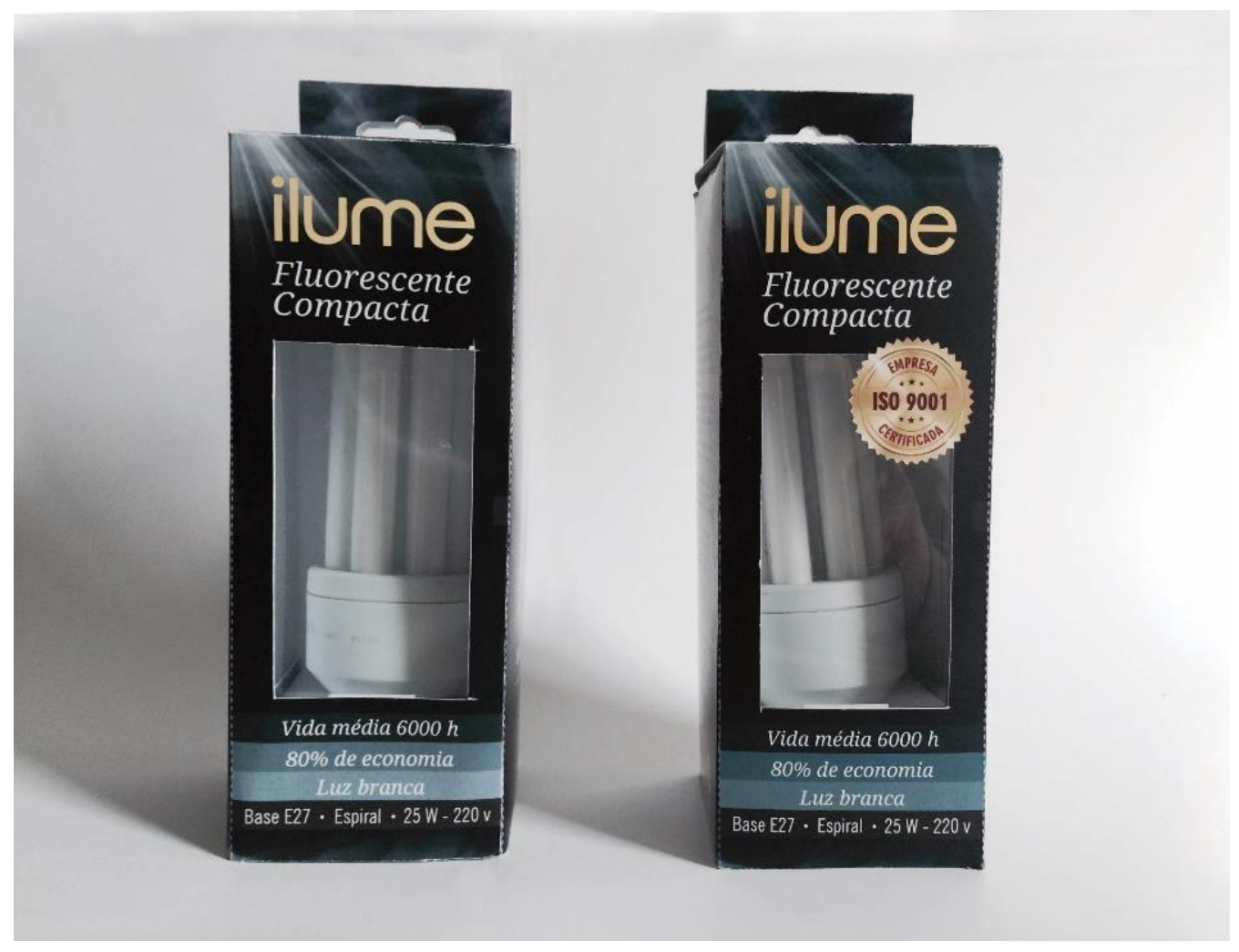

FIGURA 2 - TESTE PILOTO B (EMBALAGENS E2 E E3)

FONTE: autores (2014)

Os alunos que foram submetidos ao teste piloto verificaram que a única diferença entre as duas embalagens era o selo e, por esta razão, todas escolheram a embalagem com selo, mesmo sem saber ou tendo pouco conhecimento do que significa ISO 9001:2008. Segundo o relato dos próprios participantes, o selo transmite uma certa credibilidade ao produto, se os produtos e a embalagens são iguais, o selo se torna evidente e torna-se

o motivo da escolha. 
Diante do resultado do teste piloto, com embalagens com design igual, realizouse uma adequação para a aplicação do estudo pelo fato da escolha dos participantes ter sido pautada pela diferença, ou seja, uma tem selo e outra não. Deste modo, decidiu-se que para a aplicação do estudo o uso de embalagens com design diferente. Para tanto, foi criada uma nova embalagem, aqui chamada de E4.

\section{2 Aplicação do estudo}

Para a aplicação do estudo foi criada mais uma embalagem de lâmpada, a embalagem E4. Desta forma, foram-se apresentadas duas embalagens para a aplicação do estudo, a embalagem E3 contendo um selo de empresa com certificação ISO 9001 e a embalagem E4 sem o selo de empresa certificada (FIGURA 3). As embalagens contendo as lâmpadas foram apresentadas aos alunos participantes da pesquisa, que tiveram que escolher qual das lâmpadas comprariam. Neste caso, as embalagens de lâmpadas apresentavam designs distintos, custavam o mesmo preço e tinham as mesmas especificações técnicas, no entanto uma apresentava um selo de empresa certificada.

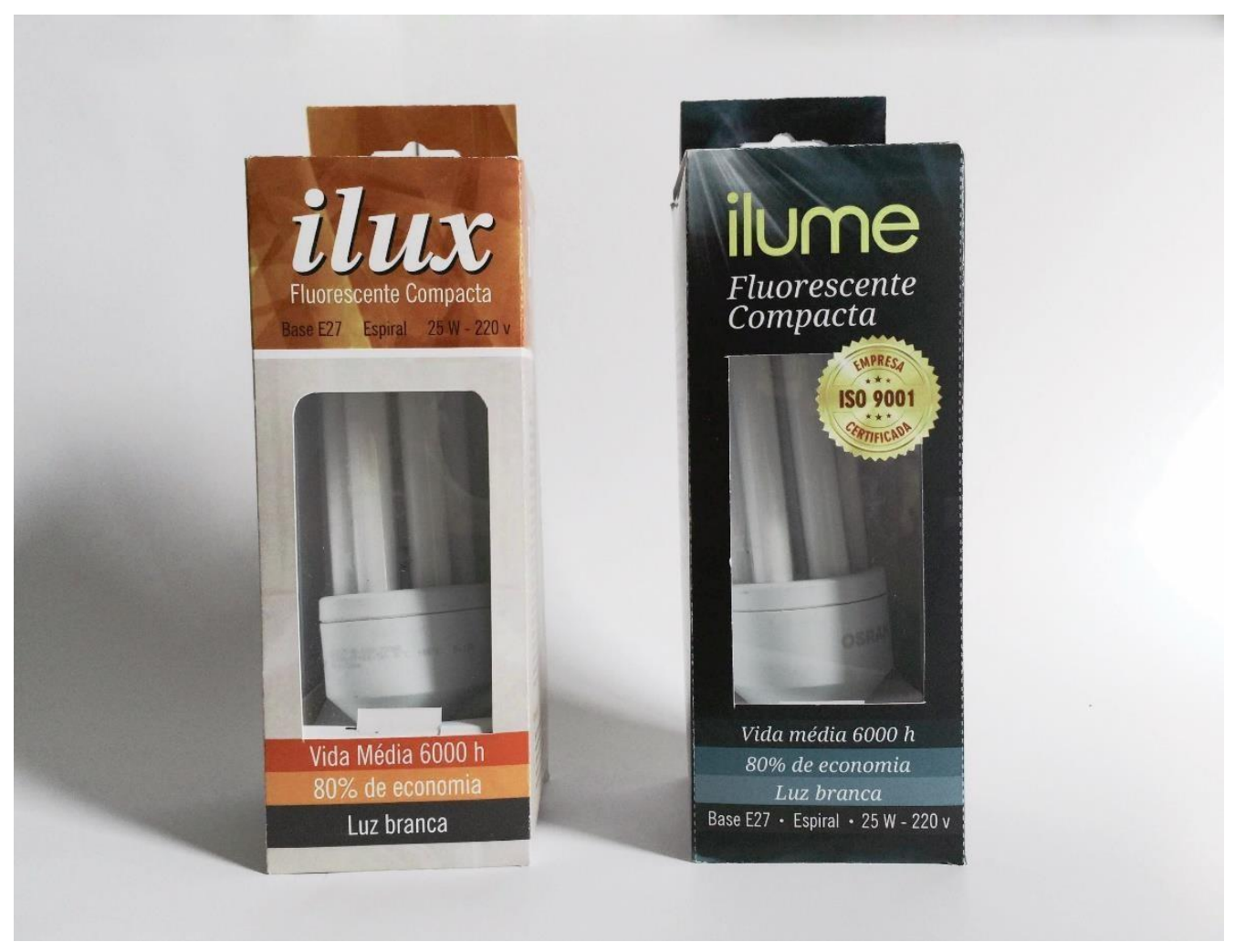


FIGURA 3 - EMBALAGENS E4 E E3 UTILIZADAS PARA A APLICAÇÃO DA PESQUISA. FONTE: autores (2014)

Durante a aplicação da pesquisa, após escolherem a embalagem, a cada participante foi perguntado qual o principal motivo da escolha e para finalizar qual o nível de conhecimento sobre a ISO 9001, para isso foi previamente definido 4 (quatro) níveis de conhecimento: nenhum, pouco, mediano e alto. Nenhum refere-se aos participantes que não conhecem a ISO; Pouco, refere-se aos participantes que ouviram falar, mas não sabem muito bem do que se trata a norma; Mediano, refere-se aos participantes que conhecem a ISO, mas não com profundidade e alto, refere-se aos participantes que conhecem e já trabalharam ou estudaram a ISO 9001.

\section{ANÁLISE DOS DADOS}

A aplicação do estudo contou com a participação de 83 (oitenta e três) alunos da UFPR, composto por 18 (dezoito) alunos do curso de arquitetura, 2 (dois) alunos do curso de matemática, 3 (três) alunos do curso de Ciência da Computação, 10 (dez)

alunos do curso de TGQ, 12 (doze) alunos do curso de TGP, 9 (nove) alunos do curso de TADS, 17 (dezessete) alunos do curso de TSE, 6 (seis) do curso de TNI, 5 (cinco) alunos do curso de TPC e 1 (um) do curso de TCI, (FIGURA 4). 
FIGURA 4 - PARTICIPANTES POR CURSO

FONTE: autores (2014)

Do total de participantes, 70\% estavam na faixa etária de 19 a 25 anos. Do total, $60 \%$ do eram do sexo feminino e $40 \%$ do sexo masculino.

Com relação a escolha do produto, na totalidade dos participantes, $98 \%$ escolheram a embalagem E3, ou seja, 80 (oitenta) estudantes escolheram a embalagem com o selo de empresa certificada, $2 \%$, que equivale a 2 (dois) participantes, escolheram a embalagem E4 e um participante se mostrou indiferente a escolha, pois tendo o mesmo valor e não conhecendo sobre a certificação, qualquer produto servia.

A pesquisa mostrou que o principal motivo de escolha do produto foi o selo de certificação, do total de participantes, 71\% escolheram por este motivo, enquanto $27 \%$ escolheram pelo design da embalagem (FIGURA 5).

FIGURA 5 - MOTIVO DA ESCOLHA.

FONTE: autores (2014)

Em relação ao nível de conhecimento sobre a certificação ISO 9001:2008, apenas $5 \%$ do total de participantes apresentaram alto conhecimento da norma, 20\% apresentaram nível mediano, $45 \%$ apresentaram pouco conhecimento e $30 \%$ apresentaram nenhum conhecimento na norma ISO 9001:2008 (FIGURA 6). 
FIGURA 6 - NÍVEL DE CONHECIMENTO DA ISO 9001:2008.

FONTE: autores (2014)

\section{DISCUSSÃO}

A implementação do Sistema da Qualidade ISO 9001:2008, possibilita a padronização e a melhoria de processos dentro de uma organização. A obtenção de benefícios derivados da ISO 9001 dependem dos objetivos e do comprometimento das organizações com a qualidade. No entanto, a adoção da ISO 9001:2008, não garante que a melhoria de processos atenda às necessidades dos clientes por meio das características do produto ou serviço.

Os fatores mais comuns entre as empresas brasileiras que buscam a certificação estão as exigências de clientes e a autopromoção.

Este estudo procurou verificar a relevância da certificação ISO 9001:2008 na influência de compra de um produto, para isso realizou-se uma pesquisa com a participação de alunos da Universidade Federal do Paraná.

0 resultado da pesquisa demonstrou que o uso de artifícios, para a autopromoção, como um selo de certificação ISO 9001, influencia o consumidor no ato da compra. Isto ficou evidenciado pelo fato de que $71 \%$ dos participantes escolheram a 
lâmpada porque em sua embalagem estava impresso um selo de certificação, mesmo que o consumidor pouco saiba sobre este selo. Este desconhecimento com relação a ISO 9001, ficou claro, pois ao somar o número de pessoas que pouco sabiam e que nada sabiam sobre a norma ISO totalizou 75\% do total de participantes da pesquisa. Observase, nesta pesquisa, que muitas decisões de compra foram tomadas com base na expectativa de que aquele selo pudesse representar algo superior ao produto concorrente, sem saber que a certificação ISO 9001, pouco tem a ver com a qualidade real do produto. Mesmo assim, o selo de certificação apresentou-se como um diferencial, já que as marcas das lâmpadas utilizadas na pesquisa eram fictícias, mas, os participantes da pesquisa, sem nunca terem ouvido falar daquelas marcas buscaram algo que pudesse transmitir maior credibilidade ao produto.

Com base no teste piloto A, verificou-se que o design da embalagem também representa um importante diferencial e possível motivo de compra por parte do consumidor. Observou-se, por meio deste teste, que a embalagem E2, mesmo sem o selo, foi escolhida por 20 (vinte) dos 21 (vinte e um) participantes pelo motivo de maior atratividade no design da embalagem.

O teste piloto B evidenciou o selo de certificação, pois as embalagens possuindo o mesmo design fizeram com que o selo fosse ressaltado. Ao empregar embalagens com designs diferentes, apareceram respostas mais interessantes à pesquisa, pois não sendo iguais, o fator design apresenta-se como um fator de escolha para o consumidor.

Alguns pontos podem ter interferidos no resultado da pesquisa. Um dos pontos relaciona-se ao fato da existência de um Curso de Tecnologia em Gestão da Qualidade no SEPT da UFPR. Desta forma, os participantes da pesquisa que sabiam da existência deste curso podem ter escolhido a embalagem com selo por terem este conhecimento. A participação de 10 (dez) alunos do curso de TGQ influenciaram no resultado referente ao nível de conhecimento sobre a ISO 9001. Caso estes alunos de TGQ não tivessem participado da pesquisa, provavelmente, o número de participantes com nenhum e/ou pouco conhecimento na ISO 9001 teriam aumentado. Mesmo com estes pontos, observou-se que esta pesquisa apresentou resultados que possibilitaram um entendimento sobre a relevância da certificação ISO 9001:2008 na influência de compra de 


\section{CONCLUSÃO E CONSIDERAÇÕES FINAIS}

Observou-se por meio desta pesquisa que os participantes pouco sabiam do que se trata a certificação ISO 9001:2008. No entanto, a maioria dos participantes escolheu o produto que estava com o selo de certificação ISO 9001 impresso em sua embalagem por acreditar que a embalagem com o selo apresentava maior credibilidade. Portanto, o uso do selo de certificação influenciou na escolha do produto por parte do consumidor.

Percebe-se que esta pesquisa apresentou alguns limites específicos, quanto ao local, participantes e método, desta forma, sugere-se que outras pesquisas sejam realizadas em outros locais, cidades e com participantes de outras universidades ou profissionais, como também, a aplicação com outros tipos de produtos. 


\section{Referências}

ABICHT, Alexandre Melo et al. Diferenciação ou necessidade na certificação ISO 9001: uma análise em duas empresas agroindustriais. In: Congresso da XLVI Sociedade Brasileira de Economia, Administração e Sociologia Rural, 2008.

ALMEIDA, H. S. de; TOLEDO, J. C. Qualidade Total do Produto. Produção, Rio de Janeirov. 2 - n. 1, p. 21-37, 1991.

ASQ - AMERICAN SOCIETY FOR QUALITY. Quality Glossary. Disponível em: <http://asq.org/pub/qualityprogress/past/0702/43qp0702.html>. Acesso em: 28 nov 2014.

BROWN, A., VAN DER WIELE, T., LOUGHTON, K. (1998). Smaller enterprises' experiences with ISO 9000. International Journal of Quality \& Reliability Management, 15(3), 273-285.

CARPINETTI, L. C. R; MIGUEL, P. A. C; GEROLAMO, M. C. Gestão da Qualidade ISO 9001:2008: Princípios e Requisitos. São Paulo: Editora Atlas, 2010.

CORREIA, L. C. C.; MELO, M. A. N.; MEDEIROS, D. D. Modelo de diagnóstico e implementação de um sistema de gestão da qualidade: estudo de um caso. Produção, v. 16, n. 1, p. 111-125, 2006. http://dx.doi.org/10.1590/S0103-65132006000100010.

CLIMENT, S. (2005). Los costes, gastos, burocracia e incremento de productividad por la certificación en la norma ISO 9000 en las empresas certificadas en la norma ISO 9000 de la Comunidad Valenciana. Investigaciones Europeas de Dirección y Economía de la Empresa, 11(1), 245-259.

D’ÂNGELO, Flávio \& NETO, João Amato. Motivações e Contradições na Implementação e Certificação de um Sistema da Qualidade. Anais ENEGEP 1997. Disponível em:

http://www.abepro.org.br/publicacoes/index.asp?num=161\&Pagina=9\&kual=mesma\& pchave $=\& a n o=1997 \&$ his_enegep=s/. Acesso em: 03 set. 2008.

FRANCESCHINI, F.; GALETTO, M.; CECCONI, P. A worldwide analysis of ISO 9000 standard diffusion. Benchmarking: na international journal, v. 13, n. 4, p. 523-541, 2006.

GIL, A. C. Como elaborar projetos de pesquisa. 4. ed. São Paulo: Atlas, 2007

GONÇALVES, J. E. As empresas são grandes coleções de processos? RAE - Revista de Administração de Empresas, São Paulo- v. 40, n. 1, jan/mar 2000a.

GONÇALVES, J. E. Processo, que processo? RAE- Revista de Administração de Empresas, São Paulo. v. 40 - n. 4, out/dez, 2000b. 
LEUNG, H. K., CHAN, K. C., LEE, T. Y. (1999). Costs and benefits of ISO 9000 series: a practical study. International Journal of Quality \& Reliability Management, 16(7), 675691.

MARÍN VINUESA, Luz María. Gestión de la Calidad Total e indicadores no financieros: reflejo del valor de la certificación ISO 9001:2000. Revista Europea de Dirección y Economía de la Empresa 22 (2013) 97-106.

OLIVEIRA, D. P. R. Administração de Processos. Conceitos, Metodologias e Práticas. São Paulo. 3‥ ed. Editora Atlas, 2009.

PELEGRINI, A. V; KISTMANN, V. B. A gestão do design e desenvolvimento de embalagens de produtos de consumo. In. Anais do Congresso Internacional de Pesquisa em Design 2003. AEND. BR/Rio de Janeiro, 2003.

PINTO, S. H. B; CARVALHO, M. M; HO, L. L. Implementação de programas de qualidade: um survey em empresas de grande porte no Brasil. G\&P - Gestão e Produção: v.13, n.2, p.191-203, 2006.

POKSINSKA. (2010). When does ISO 9000 lead to improvements? International Journal of Productivity and Quality Management, 5(2), 124-136.

TROTT, Paul. Gestão da inovação e desenvolvimento de novos produtos. Porto Alegre: Bookman, 2012.

TURCHI, L. M. Qualidade total: afinal, de que estamos falando? Texto para discussão no 459 - Instituto de Pesquisa Econômica aplicada, 1997. Disponível em: <http://www.ipea.gov.br/pub/td/1997/td_0459.pdf> Acesso em: 09 nov 2012. VENTURA, Rodrigo. Mudanças no Perfil do Consumo no Brasil: Principais Tendências nos Próximos 20 Anos. Macroplan, Prospectiva, estratégia e gestão, 2010.

WOOD, T. Jr.; URDAN, F. T. Gerenciamento da Qualidade Total: uma Revisão Crítica. RAE - Revista de Administração de Empresas, vol. 34, n. 6, 1994. 